\title{
Teaching Electrolysis Using STSE Method, Multidisciplinary
}

\author{
Approach \\ $\operatorname{Varda~Bar~}^{1^{*}}$, Ebtisam Azaiza ${ }^{2}$, Dima Azaiza ${ }^{3} \&$ Aviv Spector Shirtz ${ }^{4}$ \\ ${ }^{1}$ School of science Education, Hebrew University of Jerusalem, Israel \\ ${ }^{2}$ Sakhnin College Academic College for Teacher Education, Israel \\ 3 Department of developmental biology and cancer research, Institute of medical research \\ -Israel-Canada, The Hebrew University of Jerusalem, Israel \\ ${ }^{4}$ The Department of History, Philosophy and Sociology of Sciences \& The Edelstein Center for the \\ History; Philosophy of Science, Technology and Medicine, The Hebrew University of Jerusalem, Israel \\ *Varda Bar, E-mail: barvarda@zahav.net.il
}

\begin{abstract}
The paper presents a case study aimed at introducing electrolysis to a group of high school students. The instructional method consisted of hands on experiences and discussions undertaken in a facility for highly motivated students with access to high quality equipment. The method of instruction is not used in schools where the students study daily, nor did they learn electrolysis within their regular curriculum. The instruction was built on experimenting with the basic scientific concepts of electrolysis together with understanding technological applications. Learning included the concepts of ions, reduction potentials and being exposed to the way current is moving in an aqueous solution, in contrast to the electrons that carry the current in metals.

The instruction consisted on 15 sections; the duration of each was 90 minutes. The involvement was done through the method of pre-test, instructional set, and a post-test. The post-test revealed difficulties found in the previous literature concerning this discipline. A T-test showed a significant difference between the pre and the post-test results. Curricula suggestions to improve the teaching of both the electrolysis cell and the Galvanic cell are offered. All the students said that they enjoyed the method of instruction and wished to continue to learn according to the same method in their school. The paper is preceded by a short description of the history of electrochemistry and concern for pupil's difficulties.
\end{abstract}

\section{Keywords}

electrolysis, electrolysis cell, galvani cell, half-cell, Ions, history of electricity, constructivism, high-school science 


\section{Introduction}

The research described is this paper consists on the Science Technology and Society and the Environment (STSE) curricula design and the constructivist approach to science education. STS is a curriculum design method that emphasizes the mutual relationship between science and technology and their effects on the society. In this research, we presented the mutual relationships between the scientific and the technological aspects of electrolysis toan $11^{\text {th }}$ grade class of highly motivated girls, learning in a school at east Jerusalem. Electrolysis was presented to the pupils through hands on experiences and investigative discussions according to the constructivist approach to the teaching of science. The research was carried out by using a pre-test, involvement and post-test. The involvement took place in a special facility for high achieving and motivated pupils, as enrichment for their learning of standard curricula in their school. The course took place twice a week and consisted of 15 meetings of 90 minutes each.

The subject of electrolysis was chosen since it can be defined as a crossroad between physics, chemistry, technology and the environment, which makes it a perfect candidate for Science, Technology, Society and the Environment (STSE) curricular design. The pre instructed views of the pupils which surfaced in the pre-test, the experiences, the discussions and the use of questions asked by the pupils, all aimed to cause a conceptual change (Posner et al., 1982). Post-test results showed significant developments in the pupils' achievements; and pointed to some difficulties that remained even after the involvement; some may resulted from the style of some specific questions.

The main difficulties that were observed during this research were:

1) Pupils thought that electricity can be conducted by electrons in the bridge of the electrolysis cell, as well as in the cell itself.

2) Pupils' difficulties regarding the definition and calibrations of the potentials of the half-cell.

3) Difficulty in the identification of the anode and the cathode in both the battery and the electrolysis cell.

\subsection{The Place of Electrolysis in the Sciences}

As stated previously, since the science of electrolysis is situated at the crossroads of electricity, chemistry technology and the environment, it is a perfect candidate for STSE instruction. As such, it is a component of the curriculum of Physics and Chemistry. The emergence of electrolysis as a particular scientific development in its own right, created a new source for electric force, utilizing chemical reactions replacing mechanical ones. The change in the curriculum used in the elementary and medium school was due to the emphasis on current rather than force, was made since continuous electric current is easily created from the battery, contrary to the former experiences of mechanical rubbing which resulted with sparks. The change is also due to the electrical applications of electricity by the use of currents. Thus, most recent instructions of electricity at schools are based on batteries, bulbs and currents. It is proposed here to emphasize the concept of electric forces in order to eliminate misconceptions such as non-conservation of the current. 


\subsection{Historical and Theoretical Background}

The view of electricity as electrostatics originated in 400BC (Park, 1989), and did not change for more than thousand years. During this period materials were classified as those that can be electrified and those that cannot, a classification depended on the ability to exert electric force by rubbing of the different materials.

The view of electricity as nothing more than electrostatics was challenged during the first half of the $18^{\text {th }}$ century, when Stephen Gray $(1720,1731)$ discovered the fact that electricity can be experienced away from the point where it was induced. In order to find the extent of the effect of the exerted force, Gray conducted experiments using different lengthens of wires. When his wire was too long to be held, Gray hung his wire on the ceiling by a copper wire and the electrical effect stopped. Unfortunately, since Gray still used the old classification scheme between materials that can be electrified, and those that cannot, he explained his observation by the statement that: "copper cannot be electrified". Moreover, he thought that materials that cannot be electrified "kill" the electricity.

Charles François de Cisternay du Fay (1734), on the other hand, changed the classification system to conductors and non-conductors, and explained Gray's observations according to his new classification scheme. He also claimed that any matter can be electrified if it is isolated from the environment by a non-conductor; and that electricity may move in non-conductor if the electric force is strong enough. These two ideas made his interpretation more fruitful and induced a conceptual change (Posner et al., 1982) that paved the way for Benjamin Franklin's (1771) electrical interpretation of lightning; and to several technological findings such as the Leiden jar and the Electroscope. Du Fay (1733) also discovered the fact that there are two kinds of electricity, defined today as positive and negative, and the forces between them. This led to an argument regarding the electric currents: is it one directional fluid, according to Franklin; or bi-directional according to Du Fay? Later, in the study of electrolysis, it was discovered that current may be unidirectional (by electrons) or bi-directional (by ions) in different situations.

The beginning of modern electricity can be stated to the year 1791, with Luigi Galvani's observation of a shock that occurred to a frog leg held by two metals (Whittaker, 1951). The researches of Volta and Alessandro Galvani attributed the phenomenon to electricity. Galvani interpreted it as a special property of a force of living bodies. The conductivity of humans and animals was known to both researchers by the presentations of Gray in which electricity was applied to a human held by non-conducting ropes; electricity was applied at one place, and electric sparks where observed at various other points emitted from the body. 


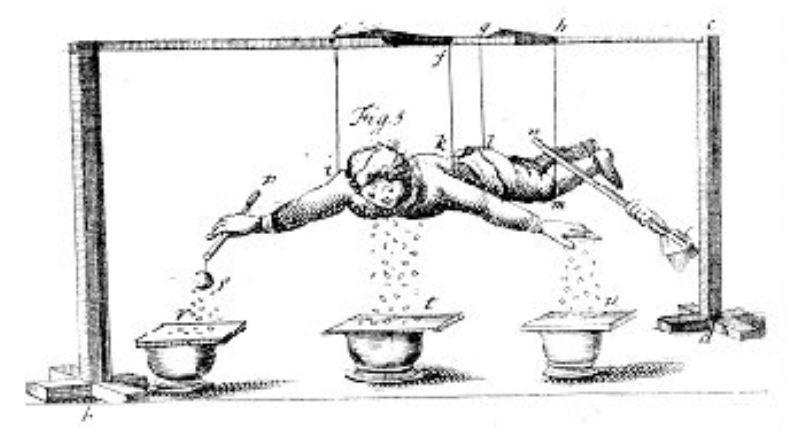

Figure 1. Electricity Passes through a Human Body

Volta (1816) observed the same electric shock as Galvani in settings which were unrelated to living (or dead) bodies; two different metals attached to a piece of cloth soaked with acid demonstrated the same effect as the body. This was the first electric cell-the first battery. Later, he developed the pile: a set of electric cells made of different metals with acid between them, a device which strengthened the electric force, thus extending the means to generate electric current. This development induced a conceptual change (Posner et al., 1982), since Volta's explanation was more logical, plausible and fruitful the previous one offered by Humphrey Davy (1808) and Michael Faraday (1834).

The discoveries and inventions that followed Volta (1816) and Galvani (Whittaker, 1951) were adopted in the experiments of Davy, who enhanced the pile and used it to extract metals from their compounds. These applications bridged physics, chemistry and technology, as electrochemistry. The main concept used in electrochemistry is the ion-electrically charged particle in aqueous solution, and carrier of electricity in water solution (The present meaning of the ion is an atom or a molecule in which one or more electrons are missing or with one or more additional electrons). Since the ions carry charge, they are influenced by an electric field and can move in it. This definition is related to the structure of the atom as found later by Ernest Rutherford (1911) and Niels Bohr (1913) in the $20^{\text {th }}$ century, but the idea of the moving charge starts with the English physicist and chemist Michael Faraday in 1834. The word ion is the Greek ióv, "going", that contains the present participle of ícval, ienai, "to go". This term was introduced for the unknown electric force that acts in certain solutions-creating motion in them. Faraday (1934) named the electric species that "goes" from one electrode to the other, through the aqueous medium ions. Faraday did not know the nature of these species, but he knew that metals dissolved into and entered the solution at one electrode, and metal emerged from the solution at the other electrode, by electricity. He assumed that some kind of substance moved through the solution in a current, conveying matter from one place to the other and called the matter ions when attached to the electric source. Faraday also introduced the words anion for a negatively charged ion, and cation for a positively charged one. In Faraday's nomenclature, cations were named so because they were attracted to the cathode in a galvanic device and anions were named due to their attraction to the anode. Ions have a role in both the 
battery and in the electrolysis cell. Note that in the electrolysis cell the anode is the positive electrode (attracting the anions), and the cathode is the negative one (attracting the cations).

The battery, as invented by Volta was made out of two different metals (Early practical batteries used copper and zinc as electrodes), and a conducting solution between them, as shown in Figure 2.

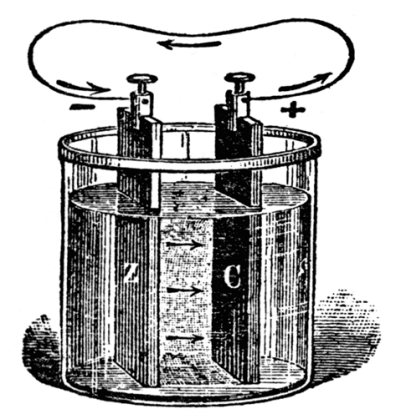

Figure 2. Volta Battery, a Photo of Volta Cell, Current Direction Us from + to - ; Electrons Move from - to +

In later batteries, the copper was replaced by coal, and an oxidizing agent was added to absorb the emitted hydrogen that may reduce the activity of the cell. Modern batteries contain lithium instead of zinc, in order to create a higher reduction potential (seelater). Not with standing, these changes in the battery, it still retains the basic structure suggested by Volta and used by Davy. This basic structure allows the battery to convert chemical energy into electrical potential energy, and thus static electric force is created.

The opposite process is exemplified by the current generated by the battery and used in the electrolysis cell to produce chemical energy (Figure 3). The earliest electrolysis cell was a non-conductive container filled with a conducting liquid, in which both the positive and the negative electrodes were inserted, as demonstrated in Figure 3:

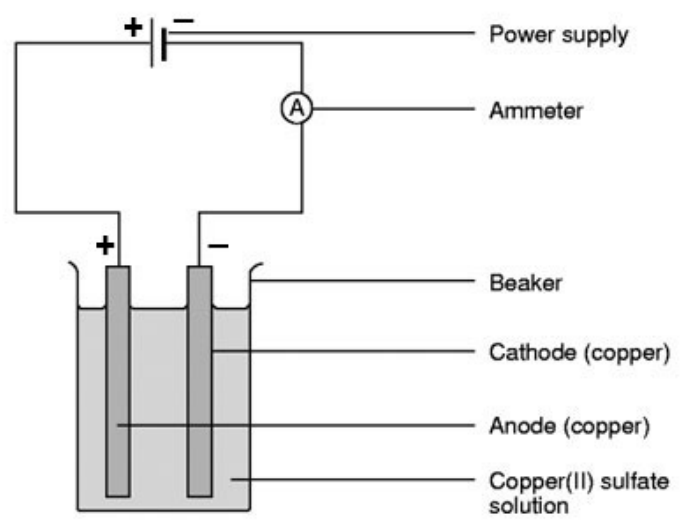

Figure 3. Electrrolysis Cell 
The modern cell is divided into two half-cells, one for the positive electrode and one for the negative electrode. A tube that contains the electrolytic liquid connects the half-cells, thus the compounds which are being generated near the electrodes do not mix; this is the salt bridge (Figure 4).

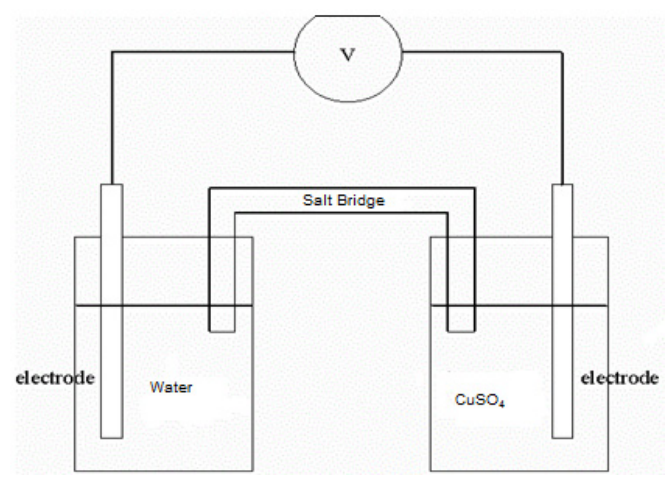

Figure 4. Advanced (Modern) Electrolysis Cell

The same technology is also used in the modern battery (Figure 5):

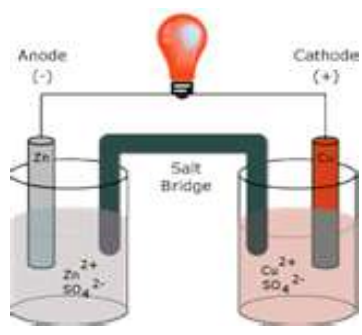

Figure 1. Galvani Cell-A Battery Containing a Bridge

To extract the current from the battery, the two electrodes of the battery are connected to conducting metal wires. These current conducting devices are connected to the electrodes of the electrolysis cell, or to other electric devices. This structure embodies the connection of these devices to physics, chemistry and technology. The ideas about the structure of the atom and the ion are physics related, while the connection to chemistry is due to Faraday's laws (1834), especially to the second law, which connects the electricity to the chemical concept of the valence. Formulating these laws and giving a more general classification of isolators and conductors, are among the reasons Faraday is the leading light of electrolysis.

Among the myriad contemporary technologies which rely on electrolysis are for example the important process of extracting elements (electrolysis of water), and includes extracting active metals such as aluminum and sodium; and nonmetals elements such as chlorine; making sodium hydroxide; electro plating; advances in the design of batteries and accumulators; cleaning water; anodization of metals to reduce corrosion. Some more recent uses are producing oxygen for space crafts and nuclear submarines, 
and extracting hydrogen as fuel. These applications that extend the early applications of Davy, justify the instruction of electrolysis to high school and college students. Our research uses ideas taken from the history of chemistry and physics in order to impart knowledge of electrochemistry as reduction potentials, and exemplify technological uses.

\subsection{Students'Alternative Conceptions Regarding the Electrochemical Cell}

Research literature suggests that students enter chemistry classes with pre-conceived ideas about the natural world (Duit, 2009; Wandersee et al., 1994). These ideas lead students to make predictions and provide explanations different from currently accepted scientific conceptions, called alternative conceptions (Herron \& Nurrenbern, 1999). Because learning occurs by construction of knowledge in the mind of the learner (Bodner, 1986), when the learner tries to assimilate new information into his or her existing knowledge structure, former ideas may affect this process. Previous research found that electrochemistry is especially difficult subject for the student, since many prior alternative concepts can be traced (Driver \& Oldham, 1986). Thus, the teaching of electrolysis requires both revising and eliminating existing knowledge. To improve instruction techniques, pupil's difficulties were identified by prior studies, and were researched as part of the involvement design. It is important to state that many of these difficulties may be found in the different stages of the history described here, thus the study of history of this subject can be a useful tool for teaching. The process of eliminating and revising previous knowledge reflects the process of scientific advancement.

Allsop and George (1982) stated that students had difficulty in producing scientifically accepted electrochemical cell diagrams and in predicting the cell's reactions. Ogude and Bradley (1994) reported pre-college and college students' alternative conceptions about conduction in the electrolyte, and electrical neutrality. Students participating in their study believed that electrons flow through the salt bridge and in the electrolyte solutions. They also stated incorrect direction for the movement of either electrons or ions. This problem is basic to the discipline; metals conduct electricity due to free electrons that exist in them, but there is no movement in the opposite direction. The battery and the electrolytic cell are based on separation between positive and negative electric ions and opposite motions of them as bi-directional currents. Metals stop their functioning since they do not allow bi-directional motions of charges. In another article, Ogude and Bradley (1996) identified students' difficulties in relation to aspects of cell components, cell EMF's, current and electrode processes and terminology. The results suggested that many students believed that electrodes of the Galvani cell were pre charged. By conducting interviews with high school students, Garnett and Treagust (1992) reported six areas of conceptual difficulties that students had about electrolytic and galvanic cells (which received special attention within our research):

(a) Identifying the anode and cathode in galvanic cell.

(b) The need for a standard half-cell.

(c) Current in a galvanic cell.

(d) The charge of the anode and cathode in galvanic cells. 
(e) Identifying the anode and cathode in electrolytic cells.

(f) Predicting the products of electrolysis and the magnitude of the applied EMF between the electrodes.

Sanger and Greenbowe (1997) replicated Garnett and Treagust's (1992) interviews on galvanic and electrolytic cells and extended them to concentration cells. Students' alternative conceptions included electron flow through a salt bridge. They thought that electrons flow through the electrolyte solutions in order to complete the circuit. The students also thought that the plus and minus signs assigned to the electrodes represent net electronic charges, and that water is not reactive in the electrolysis of aqueous solutions. In addition to these alternative conceptions identified in Garnett and Treagust's (1992) study, Sanger and Greenbowe (1997) reported other students' notions including the beliefs that half-cell potentials are absolute and can be used to predict the spontaneity of individual half-cell reactions, and that electrochemical cell potentials are independent of ion concentrations. Research that is more recent reported the same difficulties also among high achieving pupils (Loh et al., 2014; Rahayu et al., 2011).

\section{The Research}

\subsection{Educational Background of the Research}

Our research is based on the STSE curricular ideas containing physics, chemistry and technological applications, together with constructivist approach to the teaching of science. The research was based on: (1) investigating students' previous ideas about electrolysis; (2) Exposing these ideas through experiences and class discussion; and (3) making an attempt to change misconceptions by performing more hands on experiences and carrying out discussions taken form SSI ideas (Tobin et al., 2011) and from the study of Niaz and Chacón's (2003). During the instruction we also emphasized the role of the reduction potential and its connection to the activity hierarchy of metals and non-metals.

\subsection{Curricular Set}

The Curricular set was aimed at giving answers to the six difficulties identified by Garnett and Treagust (1992), reflected in the curriculum experiences (E), which are described in the next section, and in the test questions $(\mathrm{Q})$, which can be found in the appendix.

The six difficulties were addressed in the following questions:

(a) Identifying the anode and cathode in galvanic cell, addressed in (Q1) and (E11).

(b) The need for a standard half-cell, addressed in (Q2).

(c) Current in a galvanic cell and the connecting bridge, addressed in (Q3) and (Q7).

(d) The charge of the anode and cathode in galvanic cell, addressed in (E10).

(e) Identifying the anode and cathode and their charge in electrolytic cell, addressed in (Q1).

(f) Predicting the products of electrolysis, was addressed in (Q6, E6, E7, E8 and E9).

(g) The magnitude of the applied EMF addressed in (Q9).

Also, (Q8) Asked about the current in the bridge, (Q4) and (E2) addressed the flow of the electrons outside the cell. To answer (Q4) correctly the charge of the electrodes in the galvanic cell should be 
known. The salt bridge is addressed in (Q5).

\subsection{Set of Experiences}

The involvement of the participants was based on a set of hand on experiences accompanied by discussions. The set of experiences contained concepts from physics and chemistry, alongside technological applications. The test followed is an abbreviation of the test of Yurok (2007).

1) (E1) Redefinition of the concepts: electric circuit, conductors and non-conductors, solution, and pointing at the existence of ions in solutions and defining those solutions as conductors. This experience is aimed to point at the way the electric current is transported through the galvanic cell and through the solution in the battery.

2) (E2) Defining and expanding the ideas of conduction in metal wires by electrons, and conduction in solutions with two kinds of ions moving in opposite direction to each other.

3) (E3) Electrolysis of water, definition of the elements oxygen and hydrogen. The fact that the volume of hydrogen is double of that of the oxygen is established, confirming the equation of water as $\mathrm{H}_{2} \mathrm{O}$. Within this experience, the connection between chemistry and electricity is initiated, since the electric current is used to separate the elements of the water.

4) (E4) Making the ideas of the former lesson (E3) significant: Revision of Avogadro's law: in equal volumes of gases under the same temperature and pressure conditions, there are equal numbers of molecules (this law is correct in ideal gases that follow the gas laws). Extending this law to dilute aqueous solutions and refining it to electrolyte solutions when some molecules split to form ions, thus enabling the transition of electrical current through the solution when electricity is exerted.

5) (E5) Presentation of Faraday's laws, Following Niaz and Chacón'sideas (2003):

A) The amounts of materials accumulated on the electrodes are proportional to the quantity of electricity used, i.e., to the multiplication of the current by the time $(Q=i \times t)$. This law connects the intensity of the current with the chemical reaction that takes place in the electrolytic cell. When experiencing Faraday's first law, the compounds that accumulate near the electrodes were identified by indicators and discussed.

B) The quantities of the material extracted are proportional to specific mass divided by the valences. In a set of electrolysis cells in series-where the current is the same, the quantities of materials are proportional to the specific mass of the materials divided by their valances. Electricity is thus connected to the chemical concept of valence.

6) (E6) Identifying materials that were accumulated on, or near, the electrode by the use of indicators. This experience is aimed at exemplifying various kinds of electrolysis processes and discussing them.

7) (E7) Coating by electrolysis. Experiment is done on three stages:

A) Before using the coating by electrolysis, an iron nail is inserted into a copper compound solution and is coated by copper. This experiment helps to establish the activity hierarchy of the metals.

B) Copper from a copper compound solution coats the negative electrode (Cathode) in the electrolytic cell. 
C) Activating an advanced method of coating to emphasize the technological aspect.

8) (E8) Electrolysis of Noah (Sodium Hydroxide). When cooking oil is added to the solution; we get on one electrode hydrogen, which where combined with oil creates margarine, on the other side we get soap made out of sodium base $(\mathrm{NaOH})$ and oil. Both compounds are extracted and identified. This experiment can be used to demonstrate the way both margarine and soap compounds are made, thus bridging the discipline of electrolysis and nutrition and general hygiene.

9) (E9) Cleaning impure water by electrolysis and evaporation. This experience is aimed at demonstrating some technological and practical uses of electrolysis, and their connection to environmental improvement.

10) (E10) Creating an electric cell from lemon and two electrodes made out of two different metals, as a version of the original electric cell of Volta. This cell is discussed and the positive electrode (Anode) and negative electrode (Cathode) are explained and defined.

11) (E11) The electrodes of a simple electrolysis cell are defined. During the discussion, it is stressed that the positive and negative signs of the electrodes are defined by the charged points of the source they are connected to. After the discussion, the pupils are asked to draw a diagram of an electrolysis cell, and identify the signs of the electrodes and the other components of the cell (similar to Figure 3).

12) (E12) Creating an electrolysis cell that contains two electrodes, salt bridge, volt meter and solutions. Near the anode we inserted three kinds of water in three separate experiments: distillated water (which does not conduct electricity), Dead Sea water (containing a high concentration of salt), and faucet water (containing a small amount of salt). The copper compound was inserted near the cathode. At this point, the fact that a DC power is needed for electrolysis is emphasized, the role of the salt bridge is explained, and the concept of half cell is defined.

The experiences were carried out during 15 meetings (90 minutes each). Some of the experiences were longer than one meeting, and some needed long discussions. In order to make the principles we wished to emphasize more transparent, most of the experiences were initially done in an electrolysis cell of one container with two electrodes inserted in it.

\subsection{Method of the Research}

The research was aimed to achieve a conceptual change (Niaz \& Chacón, 2003), and was carried out according to the constructivist approach for teaching and learning science (Driver \& Oldham, 1986): emphasizing the initial pre instructed knowledge and concepts of the learners as a base for their further learning. The instructional involvement was preceded by a Pre-test; the results of Pre-test were considered through the experiences, each of them was followed by discussions. The research was concluded by a post-test which was identical to the pre-test (See test in the appendix, and note that it did not include Faraday laws). Each meeting started with a discussion aimed to define the purpose of the experience, included a description of the needed equipment, and set the sequence of each experiment to be carried out. Carrying out the experiment was followed by discussing its results and the conclusions. The discussion also included the connection of the activity to technological and environmental 
consequences such as purifying water, making electricity from citrus fruit, plating, etc.

\subsection{Population and Sample}

In the research of Rahayu et al. (2011), it was mentioned that only a limited number of researchers focused on students from non-western regions (such as Asia and the Middle East). The present research focuses on a group of East Jerusalem Arab students, thus adds one more Middle Eastern group. The research uniqueness is exemplified by its special population and the place of instruction where it was performed. The population from which the sample of the research was chosen is situated in east Jerusalem, characterized by its low economic and educational level. To attack this situation, a group of 25 high achieving high school girls were picked for this project as an enrichment of their scientific experience. The group was instructed in a special facility for pupils motivated to learn science and technology, a facility equipped to carry out hand on experiential leaning using sophisticated equipment. The girls attended this location once a week for a period of fifteen weeks. The east Jerusalem population is usually instructed through books, pencil and pen; hence they lack research skills, equipment operation skills and logic enhancement activities. Some difficulties in the experiments and tests can be attributed to this lacuna. The population of east Jerusalem is characterized by high level of discipline and is not used to the cooperative teaching method which encourages active participations in experiments and active involvement in discussions. The effect of these characteristics on the results will be discussed. At the end of the course, the participants expressed their enjoyment of this method of instructions (Bar \& Azaiza, 2001), expressed their wishes to continue to learn in this way also about other disciplines.

Another factor which should be addressed is that he instructor was a female Arab teacher with a $\mathrm{PhD}$ in chemistry, and researcher in diabetes. Instruction thus was carried out in Arabic. The teacher was encouraging and patient, letting the pupils to express their views, and gradually encouraged change of their pre-views. The equipment and its uses that the pupils were not acquainted with, was slowly introduced, and every part of each experiment was summed up and thoroughly explained.

\section{Results}

Table 1. General Results of Electrolysis Test (See Appendix for Test) No. of East Jerusalem Pupils is 25. The Results are Given in Numbers of Pupils

\begin{tabular}{lllll}
\hline $\begin{array}{l}\text { Question } \\
\text { number }\end{array}$ & $\begin{array}{l}\text { Pre-test } \\
\text { correct answers }\end{array}$ & $\begin{array}{l}\text { Pre-test } \\
\text { wrong answers }\end{array}$ & $\begin{array}{l}\text { Post-test } \\
\text { correct } \\
\text { answers }\end{array}$ & $\begin{array}{l}\text { Post-test } \\
\text { wrong } \\
\text { answers }\end{array}$ \\
\hline 1 & 5 & 20 & 10 & 15 \\
2 & 8 & 17 & 10 & 15 \\
3 & 4 & 21 & 8 & 17 \\
\hline
\end{tabular}




\begin{tabular}{lllll}
\hline 4 & 3 & 22 & 16 & 9 \\
5 & 18 & 7 & 19 & 6 \\
6 & 5 & 20 & 18 & 7 \\
7 & 2 & 23 & 0 & 25 \\
8 & 0 & 25 & 18 & 7 \\
9 & 2 & 23 & 22 & 3 \\
Mean & 5.2 & 19.8 & 13.4 & 11.7 \\
\hline
\end{tabular}

Table 1 presents the numbers of wrong and right answers in the pre-tests and the post-tests, and the changes between the pre-test and the post-test which is reflected in the changes in the achievement means. The results appear conclusive since differences between the numbers of pre-test and the post-test correct answers are significant, with T-tests value of $(\mathrm{P}<0.005)$. Nonetheless, observing the particular results of the post-test escapes some problems. Table two shows all the choices of the participants in the test.

Table 2. Distribution of Answers according to the Distracters of the Auestions. The Numbers are Given in Percentages (for Test See Appendix)

\begin{tabular}{llll}
\hline Question & Option & Pre-test answers & Post-test answers \\
\hline 1 & A & 40 & 20 \\
& B & 28 & 28 \\
& C & 12 & 20 \\
& D (Correct) & 20 & 32 \\
& A & 16 & 20 \\
& B & 12 & 20 \\
& C (Correct) & 32 & 40 \\
& D & 40 & 20 \\
& A & 20 & 0 \\
& B & 24 & 0 \\
& C & 40 & 68 \\
4 & D (Correct) & 16 & 32 \\
& A (Correct) & 12 & 64 \\
& B & 40 & 0 \\
5 & C & 24 & 24 \\
& D & 24 & 12 \\
& A & 20 & 0 \\
& B & 0 & 0 \\
\hline
\end{tabular}




\begin{tabular}{|c|c|c|c|}
\hline & $\mathrm{C}$ & 80 & 24 \\
\hline & $\mathrm{D}$ (Correct) & 72 & 76 \\
\hline \multirow[t]{4}{*}{6} & $\mathrm{~A}$ (Correct) & 20 & 76 \\
\hline & $\mathrm{B}$ & 60 & 20 \\
\hline & $\mathrm{C}$ & 80 & 4 \\
\hline & $\mathrm{D}$ & 12 & 0 \\
\hline \multirow[t]{4}{*}{7} & A & 40 & 16 \\
\hline & B & 28 & 0 \\
\hline & $\mathrm{C}$ & 8 & 84 \\
\hline & $\mathrm{D}$ (Correct) & 24 & 0 \\
\hline \multirow[t]{4}{*}{8} & A & 80 & 28 \\
\hline & $\mathrm{B}$ (Correct) & 0 & 72 \\
\hline & $\mathrm{C}$ & 80 & 0 \\
\hline & $\mathrm{D}$ & 12 & 0 \\
\hline \multirow[t]{4}{*}{9} & A & 0 & 0 \\
\hline & $\mathrm{B}$ & 80 & 12 \\
\hline & $\mathrm{C}$ (Correct) & 8 & 88 \\
\hline & D & 12 & 0 \\
\hline
\end{tabular}

As demonstrated above, studies about electrochemistry (Allsop \& George, 1982; Garnett \& Treagust, 1992; Ogude \& Bradley, 1994; Sanger \& Greenbowe, 1997) provided us with an extensive list of students' alternative conceptions. We discuss results found at the Post-test stage of our research. The difference between the numbers of the wrong answers and the correct answers in the post-test is not significant, in spite of the progress made between pre and post stages. The test and its results will be discussed according to Table two.

\section{Discussion}

In this section we present an analysis of all the answers to the test questions according to miss-conceptions found in previous research. The general aims of the test were identification of the signs of the electrodes in the Galvani and the electrolysis cells, reduction potentials of half cells, chemical reactions in the cells and products found near the electrodes and to identity the electrical carriers of the current within the electrolysis cell solution and in the bridge (see Appendix). The results of the test will be discussed according to the six misconception spresented by Garnett and Treagust (1992; see section 2.2 above):

(a) Identifying the anode and cathode in a galvanic cell. This problem was dealt in questions Q1 and Q4. 10 participants (40\%) identified correctly the Ni electrode as the negative electrode since it releases electrons into the wire; while realizing the existence of positive mickel ions released into the solution 
(Q1). In Q4, the current motion towards the Ag electrode was recognized correctly, unfortunately the identification of the sign of the electrode was not asked.

(b) Q2 dealt with understanding that the potential of a half cell is fixed relative to a standard half-cell of hydrogen. Only $40 \%$ of the participants answered this problem correctly; see also Sanger and Green bowe (1997).

(c) Q3 dealt with current in a galvanic cell; only 32\% of the students identified correctly the current as carried by the motion of both positive and negative ions that exists in the cell. In this problem and others we noticed that pupils are fixed on electrons as conductors of electricity and only a minority of them defined correctly the preexistence of both positive and negative ions in the solution, when the ions create a bi-directional current within the electric solution that move in opposite direction.

(d) Participants had difficulty to identify the charge of the anode and cathode in galvanic cells. This difficulty was manifested also among the results of Q1, when only $40 \%$ of the students gave the correct answer.

(e) Some difficulties regarding the identification of the anode and cathode in electrolytic cells were found among the results of Q6 (28\% incorrect answers).

(f) Predicting the products of electrolysis and the magnitude of the applied EMF: Most of our participants $(88 \%)$ calculated correctly the potential of the cell (Q9) and predicted the correct products found near the electrodes. In contrast to Garnett and Treagust (1992), our participants did not have difficulties in identifying the products; we attribute this to the fact that products were exemplified in a few experiences (E6, E7, E8 and E9).

Regarding problems identified by other researchers (Allsop \& George, 1982), we also found that about a quarter of the participants said that there is flow of electron sthrough the salt bridge (Q5); similar to their answer to Q8. The results showed that some difficulties found in previous research were also found in this research. A notable exception is the identification of the products in which our participants succeeded.

In spite of progress which was achieved by the students, and exemplified in the post-test, there is no significant difference between numbers of correct and wrong answers at the post-test stage. The results of the present research are better than those of the control group of Yuruk (2007), but worse than his experimental group. This can be attributed to the involvement of Yuruk's pupils with CCT (conceptual change texts). Some results of the present research, even without this involvement, are statistically significant. The problem that caused most difficulties to the students, both in the pre-test, and mostly in the post-test stage, was Q7. This difficulty is due to the fact that the students were not experienced in logic arguments that contain the ideas of assertion and reason. They correctly identified the copper wire as conductor of electrons, but this reasoning is not relevant to the existence or non-existence of light in the bulb,as the electrons in the metal cannot reach the bulb, since they do not move in the solution. This problem and its analysis demands attention in future researches. 


\section{Curricular Suggestions}

The four main issues that remediation instruction should concentrate found in the results of the posttest:

1) Electrons preexist in the wires and not created by the battery; ions exist in the water solution before being exposed to electricity.

2) The current in the solution is carried by ions and is bi-directional (Du Fay, 1733).

3) The functions of the electrolysis cell and the battery, as related to the identification of the signs of the electrodes.

4) The activity hierarchy of the elements.

Regarding 1 and 2, the pupils think that ions are induced by electricity and that current is always carried by electrons. The difficulty of pupils concerning item 3 originates also from the similarity of the diagrams of the two cells, and the different sources of the signs of the electrodes in each of them. Thus an apparent mistake concerning the charges and signs of the electrodes in the galvanic and the electrolysis cell was found. To account for this finding, a detailed explanation of the way the electrodes are identified, in these two situations, will be given here to be used in future instruction. These explanation and graphics should be emphasized during instruction (see forth). Item 4 is needed for determining the EMF of the battery. Concerning these issues, it will help to internalize also other issues of the experimental set

\subsection{Electrolysis Cell (Figure 3)}

The charges and signs of the electrolysis cell's electrodes are defined according to the charge of the Voltaic cell, or any other power supply, to which the electrode is connected. The names of the electrodes are assigned according to the ions attracted to them. The anode is the positive electrode, since it attracts the anions, and the cathode is the negative electrode and attracts the cations. In most of the experiences of the instruction set, we used the simple version of the cell in order to make this principle transparent. The more advanced cell (Figure 4), using the salt bridge, is presented only at the end of the set (salt bridge is inserted for convenience in order to avoid the products found near the two electrodes from mixing with each other). In view of the difficulties found in previous research, and in the present research, this point should be emphasized in future instruction.

\subsection{Galvani Cell-The Battery (Figure 2)}

Since we note that attempts to instruct the physics of the battery at the elementary school did not succeed (Lee \& Chang, 2001; Lee, 2007), and this discipline is only instructed in high school, explanation should be supported by the theory of the battery-Galvani or Voltaic electric cell. The Galvani-Volta cell generates electric force and current when the charges in it are separated, due to chemical reactions that occurred near the two different metal electrodes that have different reduction potentials. In Figure 2 the electrodes consist of copper and zinc inserted into sulfuric acid. The zinc, that has higher reduction potential, releases $\mathrm{Zn}++$ ions into the solution that becomes negatively charged, and functions as the anode: a negative electrode, which releases the positive ions into the solution. Electrons are released into the wire (the situation is similar to Q1). The copper releases fewer 
ions into the solution and functions as the positive electrode, the cathode. In the Galvanic cell the signs of the electrode are determined by the relative number of electrons released into the wire by each element (Q1). This is the reason why they are both compared to hydrogen in order to make a scale of reduction potentials. Difficulty may arise from dealing with relative numbers (more or less electrons released to the wire, more or less ions enter the solution). These examples can be worked to be used as reading materials and base for debate to extend understanding.

The post-test showed a major problem concerning the flow of the current in the cell and through the bridge, a problem which is emphasized in Q7. Alas, Q7 deals also with the problem of the correctness of assertion and reason. Since the participants were not knowledgeable about these terms (assertion and reason), we are not sure if the result of zero percentages of correct answers at the post-test is due to this knowledge deficiency, or due to wrong identification of the conductors of the current in the cell and the bridge. In order to avoid this potential problem, the logic procedure should be interpreted and carefully discussed. In Q3 though, when a similar question was asked directly without the potential distracting logical jargon, $32 \%$ of the participants gave a correct answer.

As we stated, the operation of the battery is related to the difference in the reduction potentials between the electrodes: The difference of the amounts of positive ions released into the solution creates separation of charges, which leads to a more negative charge on one of the electrodes. The existence of ionized positive and negative particles in the solution should be stressed. An aqueous solution is needed to accept these ions, and the bi-directional current that maintain the charge separation. Putting copper wire in the bridge (Q7) would stop these reactions and motions.

\subsection{Instruction Based on History}

For a better understanding of the impact of electrolysis on science, the discipline and its instruction were set within the context of the history of science. Our approach to history of science does not mean teaching the history directly in the class. But rather designing our class experiences to accommodate a deeper understanding of some breaking points of science; such as carrying out experiments to differentiate between electrostatic and magneto-static at elementary schools within the domain of Magnet (Gilbert, 1600). Nature of science is related to choice between theories according to their influence on results in following development. When Gray and Du Fay are compared Du Fay's classification scheme and suggestions were more fruitful then Gray's.

In electricity and especially electrolysis, many concepts and processes were argued when different researchers suggested different explanations to similar observations. Fruitfulness was in many cases the reason to choose the accepted explanation. An ongoing argument occurred regarding the electric current Du Fay described it as be-directional when Franklin (William, 2005) assumed that it is unidirectional. Previous research pointed out problems, regarding introducing the battery as a source of current. We introduce the battery, as well as electrostatic, while emphasizing that electricity is not created, and the existing charges are separated (e.g., by rubbing, or through chemical reaction). Instruction will show that the electric charges already exist in the materials before inducing the 
electricity. The battery is a source of static force, and the current is created when each of the two electrodes is connected to a metal wire. Within the history of electricity Galvanic cell is presented as part of a scientific revolution which extended the means for separating electric charges from a purely mechanical source to include also the chemical reaction, when electric force and current are created. The current in the Galvanic cell is described in the class as a different kind of current than in metals carried by ions in the aqueous solution of the battery and the electrolysis cell (Faraday, 1834), and bidirectional. Energy is taken from the chemical reaction and the force is related to the difference between the reduction potentials of the electrodes. Copper is positive relative to zinc or lithium but negative relative to carbon. Thus choosing between Galvani and Volta showed that Volta was more fruitful then Galvani. Galvani related the effect to some life power, whereas Volta gave it a physical explanation that made it more fruitful by being more general and enabled the connection of several cells together. These sets of cells were used to extend scientific research resulting in formulation of the laws of electrolysis (Faraday, 1834), and to advance new technological uses of Davy and later described here. Both the scientific advances and the technological application are included in our experiment. History is thus in the essence of science and science teaching. While it can be introduced to pupils as a motivational tool which may increase student's intellectual attraction towards studying science, it can also be harnessed for teaching science itself. Following the development of the ideas, i.e., from Volta to Faraday had increased both the depth of the explanations and their clarity.

\subsection{Limitations and further Research}

This research consists of a rather short experiment with a limited number of girls coming from the special population of east Jerusalem. It was aimed to present the basic concepts of electrolysis and Galvanic cell, and the laws that govern their functioning. To evaluate electrolysis among the sciences, a multidisciplinary approach was adopted. The instruction emphasized the connections between physics, chemistry, technology and environmental effects as was exampled here. Used hand on and discussions involvement.

To improve the results of instruction and achieve better understanding of the concepts, the introduction of the CCT (conceptual Change Texts) tool is needed. Though the development was significant, an improvement should be made to affect post-test results so that the difference in numbers between the correct and incorrect answers at the post-test stage will be also significant. The evaluation of the instruction of Faraday's laws will be made in a continuation of the research, see also Niaz and Chacón's (2003). In the next implementation of this experiment, we will put even more emphasis on the history of science and on the development of the ideas.

\section{References}

Allsop, R. T., \& George, N. H. (1982). Redox in Nuffield advanced chemistry. Journal of Chemical Education, 10, 57-59.

Bar, V., \& Azaiza, E. (2001). Teaching Arabic pupils in two method of instruction. Studies in Education, 
4(2), 109.

Bodner, G. (1986). Constructivism: A theory of knowledge. Journal of Chemical Education, 63, 873-878.

Bohr, N. (1913). On the Constitution of Atoms and Molecules, Part I. Philosophical Magazine, 26(151), $1-24$.

Davy, H. (1808). On Some New Phenomena of Chemical Changes produced by Electricity particularly the Decomposition of the fixed Alkalies, and the Exhibition of the new Substances, which constitute their Bases. Philosophical Transactions of the Royal Society (Royal Society of London).

Driver, R., \& Oldham, V. (1986). A Constructivist Approach to Curriculum Design in Science Education. Studies in Science Education, 13(1), 61-80.

Du Fay, C. F. (1733). Two Kinds of Electrical Fluid: Vitreous and Resinous. Philosophical Transactions of the Royal Society, 38.

Du Fay, C. F. (1734). A Discourse Concerning Electricity. Philophical transuctios, 32.

Duit, R. (2001). Bibliography-STCSE: Students' and Teachers' Conceptions and Science Education. Retrieved from http://www.ipn.uni-kiel.de/aktuell/stcse/stcse.html

Ehl, R. G., \& Ihde, A. (1954). Faraday's Electrochemical Laws and the Determination of Equivalent Weights. Journal of Chemical Education, 31(May), 226-232.

Faraday, M. (1834). On Electrical Decomposition. Philosophical Transactions of the Royal Society, 129.

Franklin, B. (1771). Autobiography and other writings (p. 52). Cambridge: Riverside.

Garnett, P. J., \& Treagust, D. F. (1992). Conceptual Difficulties Experienced by Senior High School Students of Electrochemistry: Electrochemical (Galvanic) and Electrolytic Cells. Journal of Research of Science Teaching, 29, 1079-1099.

Gibert, W. (1600). De magnete. Gutenberg project.

Gray, S. (1720). New Experiments in Electricity. Philosophical Transactions, 31, 104-107.

Gray, S. (1731). An Account of Some New Electrical Experiments. Philosophical Transactions, 37(417), 18-31.

Herron, J. D., \& Nurrenbern, S. C. J. (1999). Chemical Education Research: Improving Chemistry Learning. Journal of Chemical Education, 76(10), 1353-1361.

Lee, S. J. (2007). Exploring pupils' Understanding Concerning Batteries-Theories and Practices. International Journal of Science Education, 29, 497-516.

Lee, S. J., \& Chang, L. Y. (2001). Primary School Pupils' Alternative Conceptions on Battery Theory and Practice. Chinese Journal of Science Education, 9(3), 253-280.

Loh, A. S. L., Subramaniam, R., \& Tan, K. C. D. (2014). Exploring Students' Understanding of Electrochemical Cells Using an Enhanced Two-Tier Diagnostic Instrument. Research in Science \& Technological Education, 32(3), 229-250.

Niaz, M., \& Chacon, E. (2003). A Conceptual Change Teaching Strategy to Facilitate High School Published by SCHOLINK INC. 
Students Understanding of Electrochemistry. Journal of Science Educations and Technology, 12(2), 129-134.

Ogude, A. N., \& Bradley, J. D. (1994). Ionic conduction and electrical neutrality in operating electrochemical cells. Journal of Chemical Education, 71, 29-31.

Ogude, A. N., \& Bradley, J. D. (1996). Electrode processes and aspects relating to cell EMF, current, and cell components in operating electrochemical cells: Pre-college and college student interpretation. Assessment of electrochemical concepts: A comparative study.

Park, B. (1989). A history of electricity. Wiley \& Sons. NY.

Posner, G. J., Strike, K. A., Hewson, P. W., \& Gertzog, W. A. (1982). Accommodation of a scientific conception: Toward a theory of conceptual change. Science Education, 66(2), 211-227.

Rahayu, S., David, F., Treagust, A. L., Chandrasegaran, A. L. M. K., \& Ibnu, S. (2011). Assessment of Electrochemical Concepts: A Comparative Study Involving Senior High-School Students in Indonesia and Japan. Research in Science \& Technological Education, 29(2), 169-118.

Rutherford, E. E. (1911). The Scattering of $\alpha$ and $\beta$ Particles by Matter and the Structure of the Atom. Philosophical Magazine, May(21).

Sanger, M. J., \& Greenbowe, T. J. (1997). Common Student Misconceptions in Electrochemistry: Galvanic, Electrolytic, and Concentration Cells. Journal of Research in Science Teaching, 34, 377-398.

Tobin, K., Fraser, B., Campbell, J., \& McRobbie, A. (2011). SSi issues in science education. In Second International Handbook of Science Education.

Wandersee, J. H., Mintzes, J. J., \& Novak, J. D. (1994). Research on Alternative Conceptions in Science. In D. Gabel (Ed.), Handbook of research in science teaching and learning (pp. 177-210). New York: MacMillan.

Whittaker, E. T. (1951). A history of the theories of aether and electricity (p. 1). Nelson, London.

William, B. J. (2005). The Origins of Positive and Negative in Electricity. Journal of Chemical Education, 82(7), 988.

Yuruk, N. (2007). The Effect of Supplementing Instruction with Conceptual Change Texts on Student's Conceptions of Electrochemical Cells. Journal of Science and Technology Education, 71, 515-523.

\section{Appendix-Test}

1. In a galvanic cell constructed by $\mathrm{Ni}$ and $\mathrm{Ag}$ electrodes, the $\mathrm{Ni}$ electrode is the anode and the $\mathrm{Ag}$ electrode is the cathode. Which one of the following statements is TRUE about the charge of the electrodes of this cell?

a) The Ni electrode is negatively charged because it releases positive ions.

b) The positive sign of the Ag electrode indicates that $\mathrm{Ag}$ has higher reduction potential.

c) The Ag electrode is negatively charged because it attracts electrons.

Published by SCHOLINK INC. 
d) The Ni electrode is positively charged because it attract ions.

2. Which one of the following statements is CORRECT about the standard reduction potential?

a) Standard reduction potentials can be measured independently without the use of other half- cell reaction.

b) Half-cell reactions are spontaneous.

c) All standard reduction potentials are measured relative to standard reduction is relative to the standard hydrogen electrode.

d) The metal which has the most positive standard reduction potential is the most reactive.

3. In an electrochemical cell (electrolysis cell), conduction through the electrolyte is due to:

a) Electrons moving through the solution attached to the ions.

b) Movement of negative ions.

c) Electrons moving through the solution from one electrode to the other.

d) Movement of both positive and negative ions.

4. $\mathrm{Ag}(\mathrm{aq})+\mathrm{e}, \mathrm{Ag}(\mathrm{s}), \mathrm{Eo}=+0.80 \mathrm{~V}$;

$\mathrm{Ni} 2(\mathrm{aq})+2 \mathrm{e}, \mathrm{Ni}(\mathrm{s}), \mathrm{Eo}^{1 / 4} / 4=+024 . \mathrm{V}$.

In the electrochemical cell drawn above, electrons from the cell flow through the: toward the:
a) Wire, silver electrode.
b) Wire, nickel electrode.
c) Wire, silver electrode and salt bridge, nickel electrode.
d) Wire, nickel electrode and salt bridge, silver electrode.

5. The function of a salt bridge in an electrochemical cell is to:

a) Form complex ions with the oxidation products.

b) Permit electrons to flow through the solution.

c) Keep the levels of liquids equal in both half-cells.

d) Allow positive and negative ions to enter and leave both half-cells.

6. What are the products at the anode and at the cathode in the above electrolytic cell? $\mathrm{Al} 3+, \mathrm{H} 2 \mathrm{O}, \mathrm{Br} 2$, and $\mathrm{O} 2$ are arranged in the order of increasing standard reduction potentials in the following way

\section{$\mathrm{A} 13 \mathrm{p} \backslash \mathrm{H} 2 \mathrm{O} \backslash \mathrm{Br} 2 \backslash \mathrm{O} 2$}

a) The anode is $\mathrm{HBr}$ and the cathode is $\mathrm{Al} 2 \mathrm{O} 3$.

b) The anode is $\mathrm{Br} 2$ and the cathode is $\mathrm{H} 2$.

c) The anode is $\mathrm{Br} 2$ and thecathode is $\mathrm{Al}$.

d) The anode is $\mathrm{O} 2$ and the cathode is $\mathrm{Al}$.

7. Evaluate the following assertion and reason listed below:

- Assertion-If the salt bridge in the picture above was replaced by a copper wire (an electrical conductor), the light bulb would be lit.

- Reason-There will be a continuous flow of electrons in the electrolyte solutions that can pass through the copper bridge. 

a) Both the assertion and the reason are correct.
b) The assertion is correct, but the reason is incorrect.
c) The assertion is incorrect, but the reason is correct.
d) Both the assertion and the reason are incorrect.

8. Which drawing best describes the current flow occurring at the salt bridge in the $\mathrm{PbCl} 2$ solution?

9. $\mathrm{Pb} 2+(\mathrm{aq})+2 \mathrm{e}, \mathrm{Pb}, \mathrm{Eo}=-0.12 \mathrm{~V}$;

$\mathrm{Zn} 2+(\mathrm{aq})+2 \mathrm{e}, \mathrm{Zn}, \mathrm{Eo}=-0.76 \mathrm{~V}$.

What is the cell potential for the above electrolytic cell?
a) $\quad+0.88 \mathrm{~V}$
b) $\quad-0.88 \mathrm{~V}$
c) $\quad+0.64 \mathrm{~V}$
d) $\quad-0.64 \mathrm{~V}$ 